\title{
Iniciativas
}

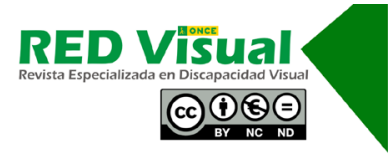

Recepción: 05-03-2021 Aceptación: 23-03-2021

\section{Retos que unen}

\section{A. M. Agüera Torres, M. I. Alcántara Moreno}

Los maestros de los Equipos de Atención al Alumnado con Discapacidad Visual de la ONCE trabajan de forma presencial con la mayoría de los alumnos, según las necesidades que presentan. Entre sus funciones están las de determinar un sistema de lectoescritura (ya sea braille o tinta), adaptar material, orientar a maestros y profesores, garantizar la adaptación a su discapacidad visual, trabajar las nuevas tecnologías, realizar estimulación visual, apoyar el currículo escolar..., entre otras.

Cuando se decretó el estado de alarma, debido a la pandemia, maestros y alumnos se vieron obligados a trabajar de forma telemática, sin apenas herramientas o ensayos previos.

Alumnos y profesores tuvieron que reinventarse, adaptarse y combatir las dificultades que iban surgiendo, que no eran pocas.

Los profesores asesoraron a alumnos y familias sobre el uso de las diferentes plataformas y se fueron adaptando a una forma de trabajo diferente, usando recursos telemáticos.

No obstante, había ámbitos imprescindibles del desarrollo de los alumnos que estaban sufriendo algunas carencias: la socialización, el entretenimiento, los juegos, la relación con sus iguales... El ánimo, la alegría y la motivación iban decayendo, y la incertidumbre no desaparecía. Por ese motivo, los maestros del Equipo de la ONCE en Jaén decidieron plantear actividades con todos los alumnos para satisfacer las necesidades lúdico-educativas, sociales y de relación con los demás, facilitando así el entretenimiento, el juego y la diversión, el buen uso del tiempo de ocio; sobre todo, el mantener el sentimiento de pertenencia al grupo..., entre otros aspectos. 
Se plantearon diferentes retos, actividades intentado implicar todas las áreas del desarrollo: culturales, emocionales, sociales, de autonomía de la vida diaria..., y que fueran compatibles con todas las etapas educativas.

El formato fue crear un grupo de WhatsApp y añadir a los alumnos o padres en función de la edad del alumno. Cada semana se iba planteando un reto motivador, que se adaptara a todo el rango de edad que el equipo atiende, y que los niños preparaban y compartían en el grupo.

Los retos que se plantearon fueron los siguientes:

- Elaborar un mensaje de ánimo para una residencia de ancianos: se propuso una actividad para elaborar un cartel, dibujo, carta, canción, vídeo, etc., para una residencia de ancianos, con el objetivo de animarlos a pasar estos momentos difíciles en los que tenían que permanecer en aislamiento. Los alumnos mostraron sus sentimientos, que hicieron muy felices a los residentes $y$, del mismo modo, ellos les devolvieron vídeos de agradecimiento.

Figura 1. Reto en la residencia

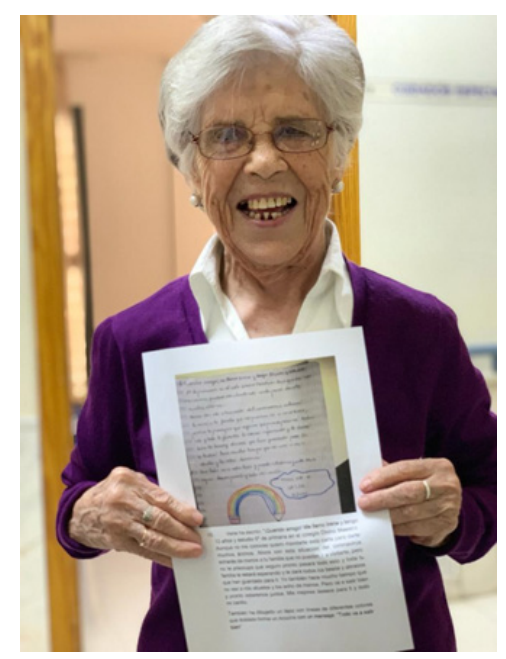

- Elaboración de un plato y presentación de la receta: actividad para elaborar un plato de comida y presentación de la receta. Cada alumno presentó un vídeo, una foto y una descripción de su receta elaborada. Todas ellas fueron recopiladas y descritas en un «recetario» que luego fue compartido para su uso con el resto de familias. 
- Elaboración de una obra arquitectónica o maqueta con materiales caseros: actividad para celebrar el Día Internacional de los Museos. Los alumnos elaboraron una maqueta de algún elemento de su localidad con la técnica plástica que eligieran, explicando las peculiaridades de esa obra.

- Descripción de un juego: actividad para describir un juego inclusivo para que todos los niños pudieran participar, explicando sus reglas y su ejecución.

Los alumnos agradecieron haber participado con sus amigos, mejorando el ánimo durante el confinamiento y promoviendo la relación social. Se logró una participación muy activa y numerosa.

Alba M. ${ }^{a}$ Agüera Torres. Maestra. Dirección de Apoyo de la ONCE en Jaén. Mesa, 16; 23001 Jaén (España). Correo electrónico: alat@once.es.

M. ${ }^{a}$ Isabel Alcántara Moreno. Maestra. Dirección de Apoyo de la ONCE en Jaén. Mesa, 16; 23001 Jaén (España). Correo electrónico: iam@once.es. 